\title{
Muscle Changes in Lambs with Surgically Created Scoliosis Produced in Utero
}

\author{
G. M. KENT, W. ZINGG AND D. ARMSTRONG
}

SUMMARY: Spinal curves may be produced in fetal lambs with three surgical techniques. These procedures vary from mere exposure of the costo-vertebral junction of three ribs through a paravertebral incision, to resection of the head and part of the adjacent shaft of three ribs. The fetal age varies from forty-nine to seventy-three days. The degree of curvature present at birth seems to increase in severity with decreasing fetal age at the time of surgery, but the type of surgical procedure does not appear to influence the severity of the curve, suggesting that the mechanical presence of the ribs does not prevent the development of scoliosis in these animals.

Histological studies of the $m$. longissimus dorsi at the apices of the curves reveal two main types of abnormality in the muscle fibers. Both Type I and Type II

RÉSUMÉ: Nous avons produit des courbes spinales chez le fétus d'agneau par trois techniques chirurgicales. Ces procédures varient de l'exposition simple de la jonction costo-vertébrale de trois côtes par une incision paravertébrale, à la résection de la tête et d'une partie du corps adjacent de trois côtes. L'âge du fétus varie de 49 à 73 jours. Le degré de courbature présent à la naissance augmente en sévérité avec la diminution de l'áge fétal au moment de l'intervention. Cependant le type de procédure chirurgicale ne semble pas influencer la sévérité de la courbe, suggérant ainsi que la présence mécanique des côtes n'empêche pas le développement de la scoliose chez ces animaux.

L'étude histologique du muscle long dorsal a l'apex de la courbe montre deux types d'anomalies des fibres musculaires. Les fibres de types I et II étaient de taille

From the Departments of Surgical Research and Pathology, The Hospital for Sick Children, Toronto, Canada.

This project was supported by the Medical Research Council of Canada.

Reprint requests to: Dr. Geraldine Kent, Research Institute, The Hospital for Sick Children, 555 University Ave. Toronto M5G 1 X8 Canada. fibers were significantly reduced in size in the biopsies taken from the side on which the surgery was performed, and there was marked alteration in the proportion of one fiber type to the other in most biopsies taken from both operated sides when compared with biopsies from unoperated twin animals.

The fetal age and amount of surgical trauma appeared to play no role in the degree of muscle alteration, suggesting that even minimal surgical trauma to the paraspinal region at any fetal age between 49-73 days is sufficient to produce significant muscle fiber abnormality and spinal curvature.

A parallel is drawn between these muscle findings and those in a number of human musculo-skeletal diseases, and suggests the possibility of a developmental defect in the pathogenesis of these diseases.

significativement diminuées dans les biopsies prises du côté de la chirurgie. Il y avait des altérations marquées dans les proportions relatives des différents types de fibre dans la plupart des biopsies originant du côté opéré par rapport au côté non opéré chez des animaux jumeaux.

L'age fétal et le degré de traumatisme chirurgical ne semblent pas jouer un róle dans les altérations musculaires, suggérant ainsi que même un traumatisme chirurgical minime dans la région paraspinale, à n'importe quel age de 49 à 73 jours, suffit pour produire des anomalies significatives de la fibre musculaire et une courbature spinale.

Nous établissons un parallélisme entre ces trouvailles au niveau du muscle et la situation dans plusieurs maladies humaines musculo-squelettiques, suggérant ainsi la possibilité d'un défaut de développement dans la pathogénèse de ces maladies.

\section{INTRODUCTION}

The authors have previously reported a technique for the production of scoliosis in fetal lambs (Kent and Zingg, 1974), using a modification of a procedure developed by Langenskiold and Michelsson in 1961 for creating scoliosis in rabbits. This procedure involved the unilateral resection of the head and part of the shaft of several adjacent ribs. The lamb model had been prepared for the testing of implantable electrical stimulating devices for use in the clinical treatment of scoliosis. It was essential to monitor pathological changes in the longissimus dorsi, the muscle to be stimulated, before and after implantation of the stimulator.

Gross and microscopic examination revealed pathological alterations in the muscle before the device was implanted. These changes were examined further in relation to the development of the curvature, with the hope that this would shed some light on the basic lesion in scoliosis.

This report describes the muscle changes seen in the l. dorsi studying two variables: the extent and the time of surgery. Surgical procedures were designed to determine the degree of trauma required to produce muscle damage and scoliosis. Then, lambs of various gestations were studied to examine the role of fetal age on the subsequent development of muscle changes and spinal curvature.

\section{METHODS}

Eleven cross bred Suffolk ewes with timed gestations were used. Four animals had twin pregnancies. Surgery was performed between forty-nine and seventy-three days fetal age of a 145 day term.

Anesthesia was induced and maintained with a mixture of $1.5 \%$ 
methoxyflurane, five litres oxygen, and five litres nitrous oxide administered through a large face mask. Endotracheal intubation was performed when a suitable depth of anesthesia was reached and positive pressure ventilation then used for the entire surgical procedure.

The ewe was placed in a supine position and the entire abdomen and chest shaved and prepared for surgery.

A thirty centimeter skin incision was made from the cranial border of the udder to the umbilicus keeping as close to the midline as possible without damaging the anterior mammary veins. The linea alba was opened and the uterus readily visualized lying in the immediate field. A gravid horn was exteriorized and wrapped in warm moist towels, these towels served to keep the small bowel within the abdomen. The fetus was located by palpation and held against the wall of the uterus and the hysterotomy done directly over its spine. The hind legs of the fetus were eased through the incision and the fetus pulled out until only the umbilical cord and head remained within the uterus. A paravertebral skin incision was made over the costo-vertebral junction of the sixth to the eighth ribs, the subcutaneous tissue was bluntly dissected, and the longissimus dorsi retracted laterally to expose the head and adjacent shaft of these three ribs. At this point, one of three procedures was performed.

\section{Procedure I}

Seven fetuses ranging in age from forty-nine to seventy-three days were used. No further dissection was done and the skin incision was closed with interrupted catgut sutures.

\section{Procedure II}

Three fetuses, fifty-two to sixty-six days were used. The procedure was indentical to Procedure I until the ribs were exposed. At this point, the rib shafts and costo-vertebral junctions were gently traumatized by rubbing the area with a small strip of sterile gauze held in a hemostat. The incision was then closed as before.

\section{Procedure III}

Only one fetus was used in this group, it was fifty-eight days old. The entire procedure as described previously (Kent and Zingg, 1974) was done, with the head and one to two millimeter section of the adjacent shaft of the three ribs resected.

In all procedures, if an excessive loss of amniotic fluid occurred, warm physiological saline was injected into the lumen of the uterus during closure of the hysterotomy.

The hysterotomy and laparotomy were closed with chromic catgut and the skin of the ewe with a continuous suture of 3-0 polypropylene.

All pregnancies were allowed to continue to spontaneous delivery. No postoperative antibiotics or hormones were given.

Radiographs were made of the entire spine of all lambs at delivery. These were made with the lamb restrained in a supine position and even tension applied to all four extremities. If curvatures were present, the angles were measured by the Cobb method.

Radiographs were repeated at three and six months and muscle biopsies were taken at six months from the longissimus dorsi, on both sides at the apex of the curve. If the animals were not curved, the biopsy was taken from the site of the original surgical operation. The biopsy specimens were snap frozen in liquid nitrogen and sectioned at seven microns on a cryostat. These stains were done on each biopsy: hematoxylin \& eosin, ATPase, succinic dehydrogenase, and Oil Red $O$. Histograms were made from each biopsy by counting 200 muscle fibers from the ATPase stained sections according to the method of Dubovitz and Brooke (1973).

Tissue sections were examined for alterations in size and shape of muscle fibers, the presence of degeneration,

TABLE I

Results of varying the surgical procedure on the development of deformity

\begin{tabular}{|c|c|c|c|c|c|c|}
\hline $\begin{array}{l}\text { Number } \\
\text { Operated }\end{array}$ & & Aborted & $\begin{array}{l}\text { Curved at } \\
\text { Birth }\end{array}$ & $\begin{array}{l}\text { Degree of } \\
\text { Curve }\end{array}$ & $\begin{array}{l}\text { Radiographi- } \\
\text { cally Normal }\end{array}$ & Other \\
\hline Procedure I & 7 & 1 & 4 & $\begin{array}{c}16 \\
53 \\
108 \\
43\end{array}$ & 1 & $\begin{array}{l}\text { I with no curve } \\
\text { but a wedged } \\
\text { vertebra at site } \\
\text { or surgery }\end{array}$ \\
\hline Procedure II & 3 & 1 & 2 & $\begin{array}{l}48 \\
14\end{array}$ & - & - \\
\hline Procedure III & 1 & 0 & 1 & 15 & & \\
\hline
\end{tabular}

fatty replacement, and alteration in fiber type or fiber type predominance.

Three unoperated animals, twins of three operated lambs, were similarly studied and the data used as control information.

After the biopsies were taken, the lambs were euthanized with a barbiturate overdose and the gross muscle changes in the paraspinal muscles recorded.

\section{RESULTS}

From eleven pregnant ewes, twelve lambs were studied: two were aborted, three were unoperated twins and nine were live born operated animals.

Table I shows the relationship of the type of surgical procedure to the development of deformity. In these small numbers, the type of procedure does not appear to affect the outcome, and four of the five animals used in Procedure I, which was intended to be a sham procedure, developed curvatures ranging from slight to severe.

The relationship between the age of the fetus at the time of operation and the degree of curvature is shown in Table II. The most severe curves occur in the animals operated on at the youngest age.

The convexity of the curves was always on the side of operation, and the followup radiographs at three and six months demonstrated no progression in the curvatures.

\section{Gross autopsy findings}

The longissimus dorsi was reduced in mass in all animals on the operated side. In the animals with severe curves, the muscle was almost totally replaced by fat, and in the three most curved animals, the unoperated muscle also showed areas of fatty infiltration. 
Muscle biopsies

\section{A. Structural Changes}

In the unoperated animals, the muscle consisted of close packed polyhedral cells of uniform size with peripheral nuclei and no areas of degeneration or fatty infiltration were seen. There was the occasional small fiber.

The greatest structural changes were seen in the three most severely curved animals. These occurred on the operated side and consisted of almost total replacement of the muscle by fat (Fig. 1).

The muscles of the unoperated side in these animals showed degenerating fibers with internal nuclei, macrophages, and fatty replacement.

The animals with small curves showed only slight structural change in the muscle fibers. There was some variation in fiber size, occasional internal nuclei, and some fatty change. The animal with the wedged vertebra and the non-deformed operated animal had some slight variation in fiber size but no fatty change.

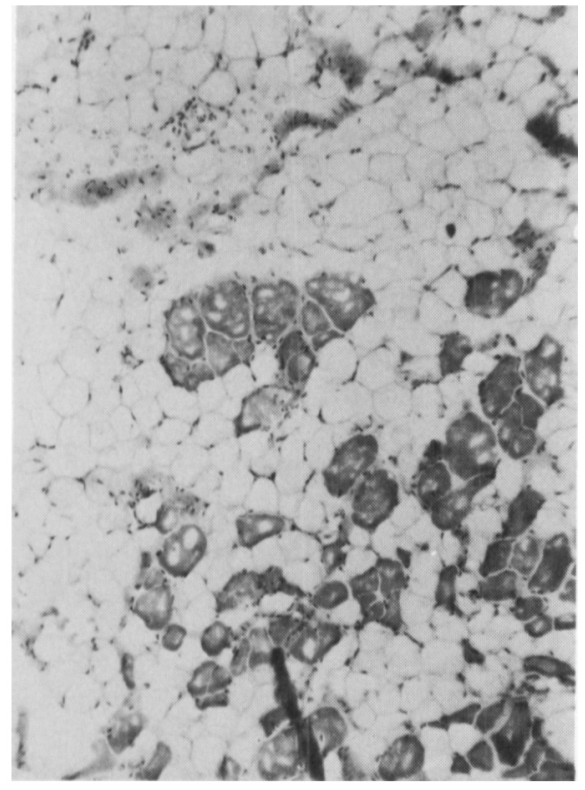

Figure 1:

(X 100) Muscle fascicle from convex side of 48 degree curvature showing marked loss of fibers and fat replacement

\section{$B$. Changes in size and fiber typing}

Table II shows a complete list of the sizes of both fiber types from the operated muscle of each animal and the relative proportion of these fiber types, expressed as the ratio of Type I/Type II fibers. Histograms were made on ATPase stained sections and succinic

TABLE II

Relationship of Age at Surgery to Degree of Curvature, Fiber Size and Fiber Proportion

\begin{tabular}{|c|c|c|c|c|c|}
\hline $\begin{array}{l}\text { Age at } \\
\text { Surgery } \\
\text { (Days) }\end{array}$ & $\begin{array}{c}\text { Degree of } \\
\text { Curve }\end{array}$ & $\begin{array}{l}\text { Mean diameter } \\
\text { in microns } \\
\text { Type I fibers } \\
\text { (operated side) }\end{array}$ & $\begin{array}{l}\text { Mean diameter } \\
\text { in microns } \\
\text { Type Il fibers } \\
\text { (Operated side) }\end{array}$ & Operated Side & Unoperated Side \\
\hline $\begin{array}{l}49 \\
52 \\
53 \\
54 \\
58 \\
62 \\
66 \\
68 \\
73\end{array}$ & $\begin{array}{c}53 \\
48 \\
108 \\
43 \\
15 \\
\text { No curve } \\
14 \\
16 \\
\text { No curve } \\
\text { wedged } \\
\text { vertebra }\end{array}$ & $\begin{array}{c}25 \\
29 \\
\text { Not done } \\
20 \\
22 \\
18 \\
28 \\
25\end{array}$ & $\begin{array}{l}31 \\
29 \\
26 \\
18 \\
13 \\
18 \\
21\end{array}$ & $\begin{array}{l}1 / 5 \\
1 / 4.6 \\
1 / 1 \\
1 / 2.5 \\
1 / 9 \\
1 / 11 \\
1 / 1 \\
1 / 8\end{array}$ & $\begin{array}{c}1 / 2 \\
\text { Not done } \\
2 / 1 \\
\overline{1 / 10} \\
1 / 10 \\
1 / 10 \\
1 / 1 \\
1.4 / 5\end{array}$ \\
\hline
\end{tabular}

\begin{tabular}{|c|c|c|c|}
\hline $\begin{array}{l}\text { Means with Standard } \\
\text { deviation }\end{array}$ & $23.8 \pm 4.06$ & $22.2 \pm 6.6$ & \\
\hline Unoperated animals & $\begin{array}{l}\text { Mean diameter } \\
\text { in microns } \\
\text { Type I fibers }\end{array}$ & $\begin{array}{l}\text { Mean diameter } \\
\text { in microns } \\
\text { Type II fibers }\end{array}$ & $\begin{array}{c}\text { Ratio } \\
\text { Typel/Type II }\end{array}$ \\
\hline $\begin{array}{ll}\text { Animal } 1 & \text { left } \\
\text { right }\end{array}$ & $\begin{array}{l}33 \\
35\end{array}$ & $\begin{array}{l}27 \\
30\end{array}$ & $\begin{array}{l}1 / 5 \\
1 / 2\end{array}$ \\
\hline $\begin{array}{l}\text { Animal } 2 \text { left } \\
\text { right }\end{array}$ & $\begin{array}{l}34 \\
34\end{array}$ & $\begin{array}{l}27 \\
31\end{array}$ & $\begin{array}{l}1 / 4 \\
1 / 5.5\end{array}$ \\
\hline $\begin{array}{c}\text { Animal } 3 \text { left } \\
\text { right }\end{array}$ & $\begin{array}{l}32 \\
37\end{array}$ & $\begin{array}{l}29 \\
33\end{array}$ & $\begin{array}{l}1 / 5 \\
1 / 5.5\end{array}$ \\
\hline $\begin{array}{l}\text { Mean with Standard } \\
\text { deviation }\end{array}$ & $34 \pm 1.8$ & $29 \pm 2.0$ & $1 / 4.5$ \\
\hline
\end{tabular}

dehydrogenase stained sections and used to verify the fiber typing. The results were similar in both types of sections.

The muscles of unoperated animals showed a predominance of Type II fibers with a mean ratio of Type I/Type II equal to $1 / 4.5$. Of fifteen biopsies studied from operated animals, six showed a predominance of Type I fibers, three were equal to the control value, and six showed a preponderance of Type II fibers in excess of the control value. Figure 2 shows histograms and photomicrographs of a control animal and one with marked Type I predominance.

The mean diameter of Type I fibers in the unoperated animals was $34 \pm$ 1.8 microns and in the operated sides was $23 \pm 8.4$ microns. This difference is significant $(p<0.01)$. There was no significant reduction in size of Type $\mathbf{I}$ fibers on the unoperated (concave) side. The two operated animals which had no scoliosis also showed a reduction in the size of these fibers taken from the side of operation.

The average diameter of Type II fibers from both sides of unoperated animals was $29 \pm 2.0$ microns and from operated sides of all the operated animals $22.2 \pm 6.6$ microns; a significant reduction at $p<0.05$. This reduction in size was present only on the side of operation.

\section{Fibre organization}

The fiber types of control animals were distributed in a typical chequer board pattern. Where sufficient muscle remained, this pattern was found in operated and unoperated muscles of all but one biopsy. This biopsy is from the unoperated side of the most severely curved animal and here the fiber distribution was changed to a sheet of Type I fibers with few Type II fibers present. Figure 3 shows the histogram and photomicrograph from this biopsy.

Fat was demonstrable histochemically in the sections stained with Oil Red $O$, in the muscles which appeared grossly fatty.

\section{DISCUSSION}

It is interesting to discover that even a relatively minor surgical procedure, performed in a small area of the paraspinal region, with no transsection of bone or muscle was sufficient to produce scoliosis and significant alteration in paraspinal muscle histology. 

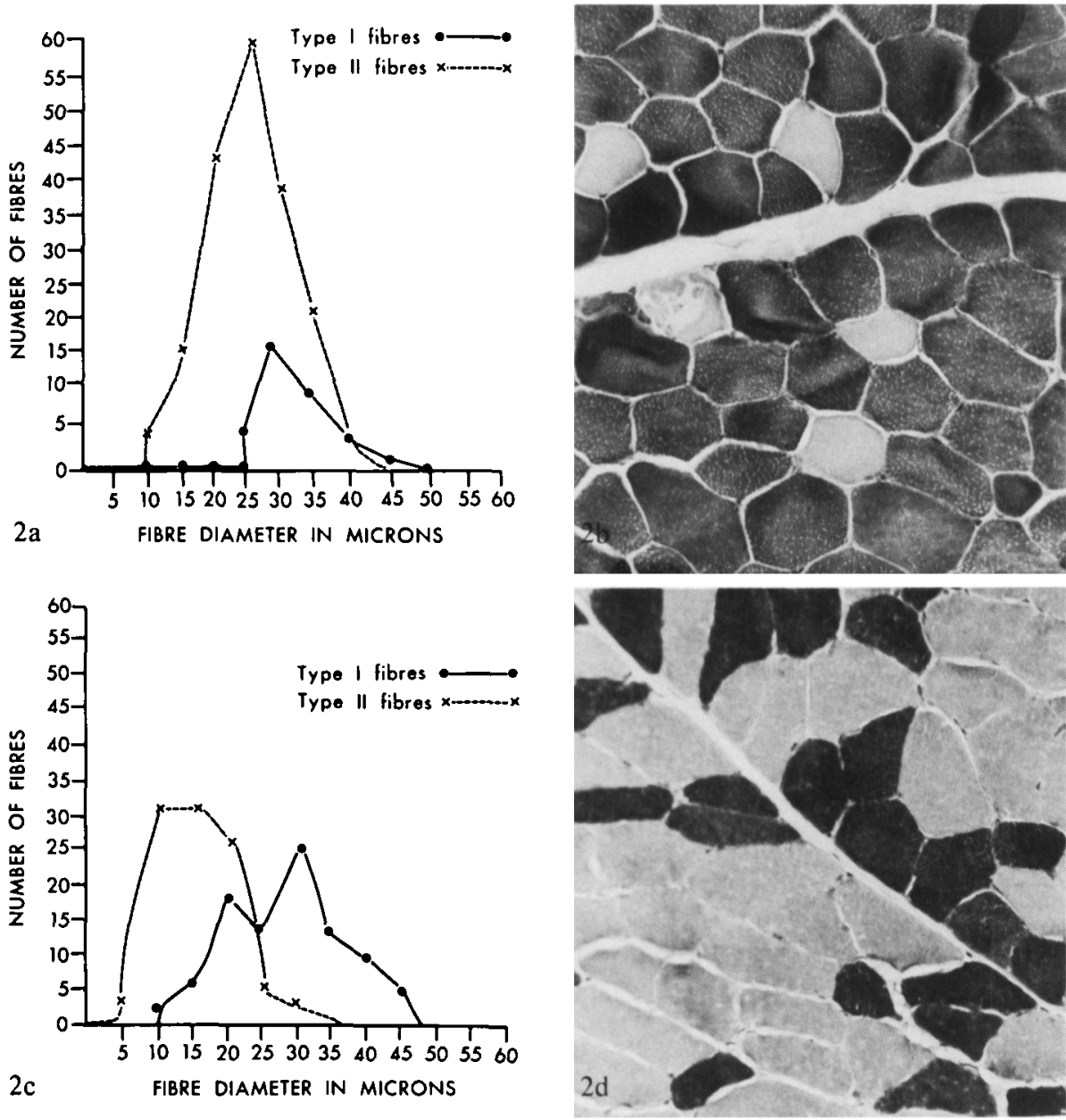

Figure 2: (X200) Muscle of unoperated animal with myosin ATPase stain pH 9.4

2 (a\&b) Type II fiber predominance

2 (c\&d) Muscle from convex side of 108

degree curvature with marked Type I fiber predominance
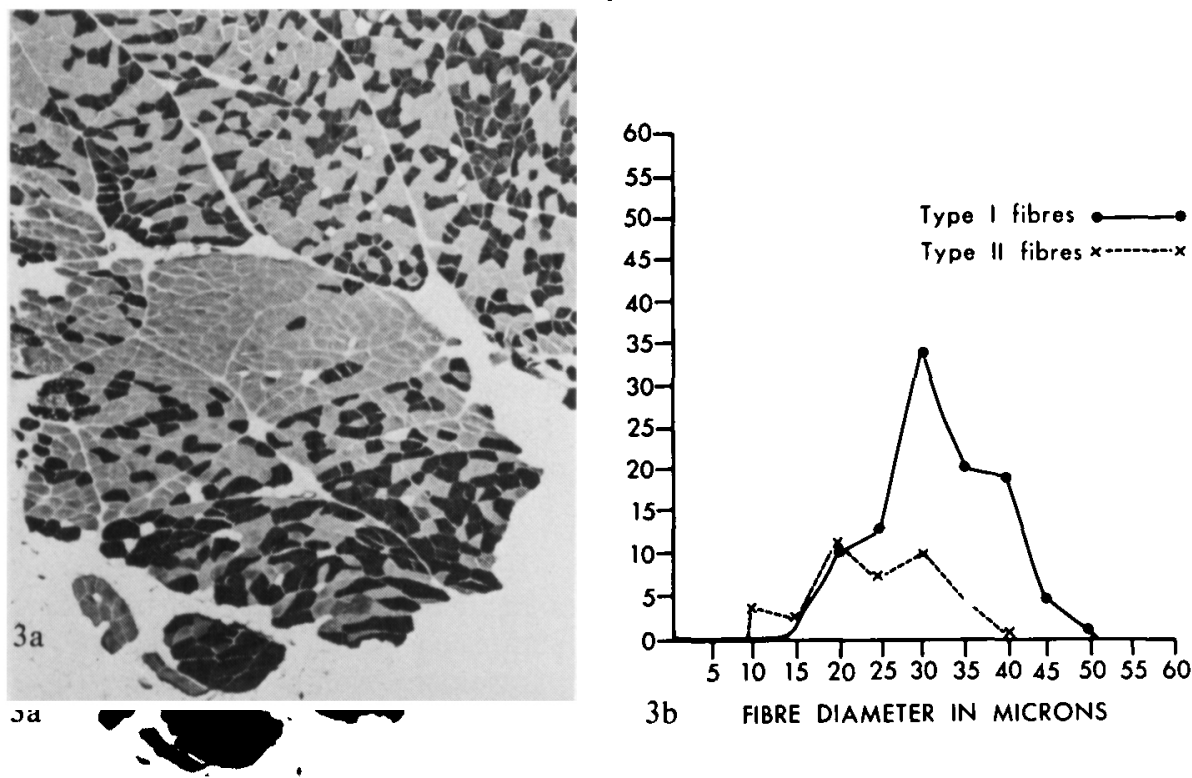

Figure 3: (X40) Longissimus dorsi from concave side of animal with 108 degree curvature 3(a) Sheet like arrangement of Type I fibers suggestive of a reinervation phenomenon 3(b) Type I fiber predominance
Furthermore, the mechanical presence of the ribs did not play a role in preventing spinal curvature.

In all the operated animals, there was a significant reduction in the size of both Type I and Type II fibers on the side of operation. The type of surgical procedure, the fetal age at surgery, and the presence or absence of curvature did not appear to influence the size reduction. This suggests that the muscle changes are not merely a secondary adaptation of the muscle to the presence of the curve, but were directly related to the intraoperative manipulation of the muscle, however minimal.

The unoperated animals in this series show a Type II fiber predominance with about four times as many Type II as Type I fibers. Since the Type II fiber is a fast twitch fiber capable of short term work related to its intrinsic anerobic glycolytic energy pathways, it is reasonable to find this type of fiber predominant in the lambs' longissimus dorsi, as this muscle is not an antigravity muscle in the quadruped, and so does not require the sustained contractile activity found in Type I rich antigravity muscles. Before seventy days fetal life, the lamb skeletal muscle shows only Type I fibers, with Type II fibers just beginning to appear at this time (Ashmore, Robinson, Rattray and Doerr, 1972). All of the lambs in this series were exposed to surgical procedures close to or during the critical period of muscle growth and the surgical trauma may have interrupted this process, producing the size reduction and wide variation in fiber proportion.

One may postulate that in some of the animals the surgery interfered with the normal symmetrical neuromuscular interaction and that the operated side lost the influences of the nervous system at either a segmental or suprasegmental level (Fenichel, Daroff and Glaser, 1964) so that the Type II fibers failed to develop in proper proportion and to adequate size (Karpati and Engel, 1968).

This hypothesis embraces the two possibilities that the typing change may represent either a release phenomenon and a reversion to an immature pattern (Karpati and Engel, 1967) or an interruption of the influences of the lower motor neuron and peripheral nerve on 
the muscle. Interference with the peripheral nerve may have induced a sprouting so that the reinervated muscle would be of one type (eg. sheets of Type I fibers).

Another hypothesis is related to decreased fetal mobility, resulting from insufficient amniotic fluid or surgical trauma to the muscle. We think that this explanation is less likely because we replaced the lost amniotic fluid with saline and we have not seen changes in intercostal or abdominal muscles in the other numerous surgical procedures which our group has performed.

The changes in the unoperated muscle deserve consideration. It is possible that there were asymmetric afferent impulses to the spinal cord at the level of the surgery, and that there were conpensatory changes in the unoperated muscle in an attempt to maintain the symmetry of the spine. The balance may have been somewhat effective in preventing progression of the curvature.

Although the mechanism of the muscle changes has not been fully elucidated by these experiments, certain facts stand out. The muscle changes occur independent of the spinal curvature and are therefore not secondary to scoliosis. The muscle changes are not related to the severity of the surgical trauma but appear with minimal injury to the paraspinal muscle. The skeletal changes seem to be related to the age of the fetus, whereas the muscle changes are not age dependent during the periods examined. Muscle and bone may follow different timetables of differentiation.

The surgical production of alterations from the normal pattern of muscle fiber types provides an intriguing model for human muscle diseases in which fiber type predominance exists eg. Type I fiber type predominance in limb girdle dystrophy, Arthrogryposis, Becker's dystrophy, chronic denervation, and idiopathic scoliosis (Hoppenfeld and Spiro, 1972) (Spencer, 1973). The changes in the lambs suggests that antenatal influences acting at a specific period in the developing human fetus may operate to produce muscle changes presenting as spontaneous muscle diseases.

\section{REFERENCES}

ASHMORE, C. R., ROBINSON, D. W., RATTRAY, P. and DOERR, L.: (1972). Biphasic Development of Muscle Fibres in the Fetal Lamb. Experimental Neurology 37, 241-255.

Muscle Biopsy: A Modern Approach. DUBOWITZ, V. and BROOKE, M. N.: (1973). W. B. Saunders: London and Philadelphia.

FENICHEL, G. M., DAROFF, R. B. and GLASER, G. H.: (1964). Hemiplegic atrophy: Histological and Etiological Considerations. Neurology 14, 883-890.

HOPPENFELD, S. and SPIRO, A.: (1972). Histochemical Findings in Paraspinal Muscles of Patients with Idiopathic Scoliosis. Presentation at the Scoliosis Research Society, Wilimington, Delaware.

KARPATI, G., ENGEL, W. K.: (1967). A New Aspect of the Trophic Function of the Motor Nerve: Influence of the Cytochemical Features of the Skeletal Muscle Cell. Neurology 17, 297.

KARPARTI, G. and ENGEL, W. K.: (1968). Correlative Histochemical Study of Skeletal Muscle after Suprasegmental Denervation, Peripheral Nerve Resection and Skeletal Fixation. Neurology 18, 681-692.

KENT, G. M. and ZINGG, W.: (1974). Experimental Scoliosis in Fetal Lambs. Surgical forum XXV, 75-77.

LANGENSKIOLD, A. and MICHELSSON, J. E.: (1961). Experimental Progressive Scoliosis in the Rabbit. Journal of Bone and Joint Surgery 43 B, 116-120.

SCOLIOSIS and MUSCLE. Proceedings of a Fourth Symposium. Spencer, G. S. G.: (1973). William Heineman Medical Books Ltd. 